\title{
A Computational Approach for Protein-Protein Interactions of Bacterial Surface Layer Protein with Human Erb3 and $\alpha I I B-\beta 3$ Receptors
}

\author{
Satyanarayana Swamy Vyshnava 1(D), Gayathri Pandluru ${ }^{1}$, Kanderi Dileep Kumar ${ }^{2}(\mathbb{D})$, Shiva Prasad \\ Panjala ${ }^{3(\mathbb{D})}$, Kameshpandian Paramasivam ${ }^{4}{ }^{(\mathbb{D}}$, Swathi Banapuram ${ }^{3(\mathbb{D})}$, Shanthi Kumari Ballapagari \\ Somappagari $^{2}$, Ramakrishna Prasad Are ${ }^{5}$, Roja Rani ${ }^{3}$, Muralidhara Rao Dowlatabad 1,* (D)

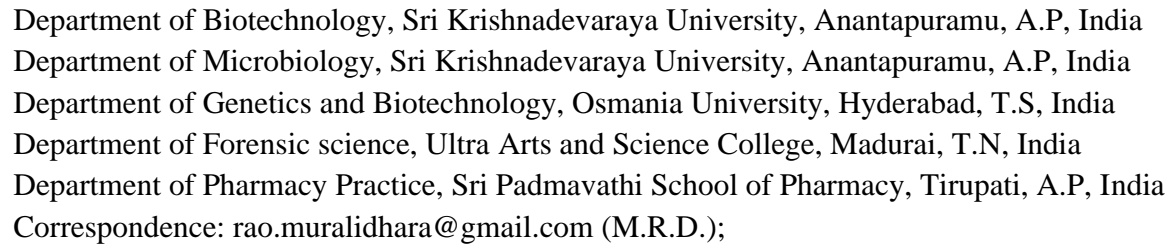

Received: 15.03.2021; Revised: 10.04.2021; Accepted: 12.04.2021; Published: 20.04.2021

\begin{abstract}
Host microbial interactions had significant factors in maintains homeostasis and immunerelated activity. One such interaction made by Lactobacillus sp. with Surface layer proteins (Slps) had been studied through a computational approach. Erb3 and $\alpha$ IIB- $\beta 3$, which are epithelial surface layer receptors, are subjected to interact with the Slp homology model. Both cell surface receptors were subjected to interact through computational docking, followed by molecular dynamics simulations through the coarse-grain method to explore the conformational stability. Through the implementation of the molecular docking for the surface layer protein A, we have shown the surface layer protein A, protein-protein interactions are higher in cellular receptors with epidermal growth factor receptor at an -34.45 $\Delta \mathrm{G}$ and -51.19 $\Delta \mathrm{G}$ through molecular docking with Erb3 and $\alpha$ IIB- $\beta 3$. This study shows the unique interaction of Slp with the epithelial surface receptors like Erb3 and $\alpha$ IIB- $\beta 3$, which are multipurpose applications in microbial-based drug therapeutics.
\end{abstract}

Keywords: anti-cancer proteins; host-microbial interactions; immunomodulators; molecular docking protein-protein interactions.

(C) 2021 by the authors. This article is an open-access article distributed under the terms and conditions of the Creative Commons Attribution (CC BY) license (https://creativecommons.org/licenses/by/4.0/).

\section{Introduction}

The upregulation and the downregulation of the cytosolic epithelial markers are the primary sources for current cancer diagnosis [1,2]. Based on the hallmark, are two main protein components are usually studied in cancer progression, which includes the predominant epithelial markers like epidermal growth factor receptor (EGFR/ Erb3) and Platelet integrin ( $\alpha$ IIB- $\beta 3$ ) [3]. The ErbB family tyrosine kinase (EGFR related protein) is crucial in the diagnosis of many cancers [4] and potential targeting drug receptors in the pharma [5-7]. In contrast, $\alpha$ IIB- $\beta 3$ belongs to the tyrosine phosphatase family who expresses antigens presence, leading to T-cells [8,9]. Due to the increasing need for reliable drug assessment and development, many studies progress on these two receptors (EGFR and $\alpha$ IIB- $\beta 3$ ) $[10,11]$. 
There is a considerable presence of normal flora through the evolution of human existence through symbiotic relationships [12,13]. These human microbial interactions are now growing a vital interest in understating the immune system's regulation as immune modulators and metabolic regulators from the past few decades [14-16]. One of the associations includes the gut microbial interactions in humans by the Lactobacillus species was well studied at the molecular level. Lactobacillus sp. is essential in human intestinal colonization; besides, they possess significant protein structure components called surface layer proteins (Slp) [17]. These proteins are outer structures of cell envelope identified in numerous other domains of Bacteria and Archaea. Slps are recognized in many species of Lactobacillus sp. such as L. acidophilus, L. buchneri, L. helveticus, L. bulgaricus, and L. brevis [18,19]. These proteins are monomolecular crystalline arrays consisting of proteins or glycoproteins subunits, whose molecular weights range from 40 - $200 \mathrm{KDa}$ [16].

Most scientific reports convey the critical importance of Slps as human immunomodulators and transducers [20-22]. The molecular mechanisms of cross-link between bacteria and the host organism system will understand the benefits and potential risks associated with the bacterial combined therapies. The immune-modulatory effect of the Slp had a significant impact on the human immune system $[23,24]$. Some research studies show the epithelial and macrophage cell line model's role in awaking innate immunity $[25,26]$. The high potency of Lactobacilli as affiliates to normal intestinal microbiota and their potential biotechnological applications has been well recognized [27,28]. Recent studies showed that the bacterial strain's binding activity with the help of Slp triggers the immune effects mainly through the host cell system's cell wall integrity by TLR4 receptors [29,30]. The proinflammatory activity of the Slp of Lactobacillus sp. may exhibit the efficacy of maintaining the human homeostasis of apoptosis and enhancing the Immunomodulation like proinflammations activating the macrophages. Considering the exclusive nature of the binding efficacy of the Slp protein towards the host gastrointestinal tract (GIT) and providing the host immunomodulatory effects, the molecular interactions between these host-microbial proteinprotein interactions (PPI) are poorly understood [31,32].

In the present study, we showed the molecular PPI in Lactobacillus brevis surface layer protein A, with the upregulated cancer cell receptors Erb3 and $\alpha$ IIB- $\beta 3$. This may provide a piece of important information in the cellular targeting of the bacterial surface layer protein's cell-specific activity towards understanding the cancers and their immune modulations during the host-microbial interactions.

\section{Materials and Methods}

\subsection{Homology modeling of the surface layer protein A (SlpA).}

Due course, in the search for the surface layer protein X-Ray and NMR models from the protein data bank (rcsb.org) [33], it doesn't provide satisfactory results us choose for the alternative method for protein structure. We used the L. brevis KB290 SlpA protein chain as a model sequence from the NCBI database (ncbi.nlm.nih.gov) [34, 35]. Swiss-model (swissmodel.expasy.org) [36] was chosen to deduce the homology model for the SlpA through the first approach mode with auto coordinates unavailability of the reference template. The generated model was recorded and analyzed for stability and nativity through the Molprobity [37], Qmean [38], and ProSA [39] online servers for the reliability of the structure for further study. 


\subsection{Receptors and ligand preparation.}

Erb3 (2L9U) [40] and $\alpha$ IIB- $\beta 3$ (2KNC) [41] protein cell receptors were searched and adopted from the rcsb.org (protein data bank), based on the Lactobacillus sp. bound to the GIT. The receptors are directly downloaded to the discovery studio client [42] and Swiss-Pdb viewer [43] through the application search. The protein structures (2L9U and $2 \mathrm{KNC}$ as the receptor and SlpA as a ligand) are refined and energy minimized through the application tools by removing the heteroatoms and water molecules to achieve the absolute structures for molecular docking.

\subsection{Molecular docking.}

Considering the large volume of atomic events for PPI, the molecularly docking was done using Cluspro 2.0, a CAPRI-based docking assessment [44], and PatchDock is a surface geometry-based ranking system [45] web server application. The generated results from the respective web servers are verified for the ranking patterns and analyzed for the effective PPI process.

\subsection{Molecular simulations.}

The flexibility and rigidity of the protein and PPI are the most critical factors in establishing the protein's stability during the interactions under physiological conditions. Based on the assessment of B-factors and rmsf values for a given protein, residual fluctuations provide detailed evidence of conformational stability. This operation was done using the CABS-Flex 2.0 webserver [46].

\section{Results and Discussion}

The structural data, as shown in Figure 1, of L. brevis KB290 from the NCBI and SwissModel database, shows that it is a polypeptide with a single chain consists of 469 amino acid with a large part of A (Alanine), T (Threonine), S (Serine), G (Glycine), V (Valine), K (Lysine) and $\mathrm{Y}$ (Tyrosine) amino acids, which contain $90 \%$ of $\beta$-sheet secondary structure, $8 \%$ loops and $2 \%$ of $\alpha$-helix in the SlpA protein structure. The Swiss-model prediction of SlpA structure shows a factor of $Z=-5.6$ conformational confidence and $65 \%$ coverage of structural database for proteins. The conformational stability of the SlpA was verified by the results of the Ramachandran plot of the protein (SlpA.pdb file) generated from the Swiss-Model with Qmean integration provided the basic aspects of the protein structure in its tertiary form with allowed 97.9\% conformation was established with highly favored regions around $90.6 \%$ of the structure which are shown in Fig ESM_1 and Fig ESM_2.

The docking scores generated from simple CPU-based program execution with little manual inference in ClusPro 2.0 webserver provided the results organized in ranked by the program to its lowest energy scores among all the clusters for each interaction to compare and illustrate the interactions. The Lactobacillus sp. binding to the host intestinal receptors was still poorly understood $[32,47]$. Here in this study, we approach getting the protein, which involves the signal transduction's surface receptors, affecting cells' growth and development, including the Erb3 and $\alpha$ IIB- $\beta 3$.

The Erb3 (PDB ID 2L9U) transmembrane heterodimeric protein, a tyrosine kinase receptor, belongs to the epidermal growth factor receptor (EGFR/ERBB) family domain helps 
in the regulation of cell growth and development. The scores from the interaction of SlpA to Erb3 include the lowest energy scores based on the coefficient weights of balanced, electrostatic, hydrophobic and Van der Waals interactions; these scores were $-1048,-1120$, -1507 and-138.4, respectively. While the $\alpha$ IIB- $\beta 3$ (PDB ID 2KNC) platelet integrin transmembrane heterodimeric protein, which is a platelet cell membrane receptor for platelet function and homeostasis. The scores from the interaction of SlpA to Erb3 include the lowest energy scores based on the coefficient weights of balanced, electrostatic, hydrophobic and Van der Waals interactions; these scores were $-1111.6,-1082,-1714$, and -435 , respectively, the compared results are mentioned in Table 1.

(a)
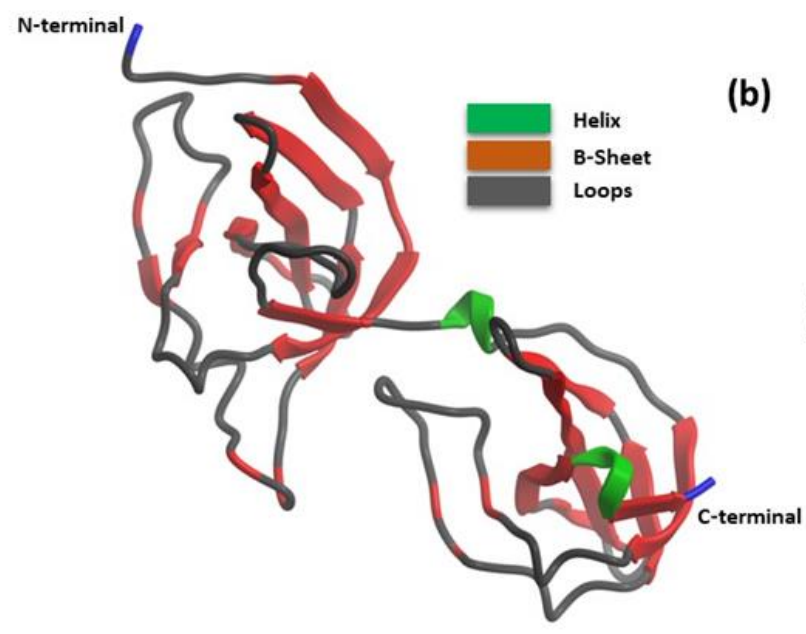

(b)

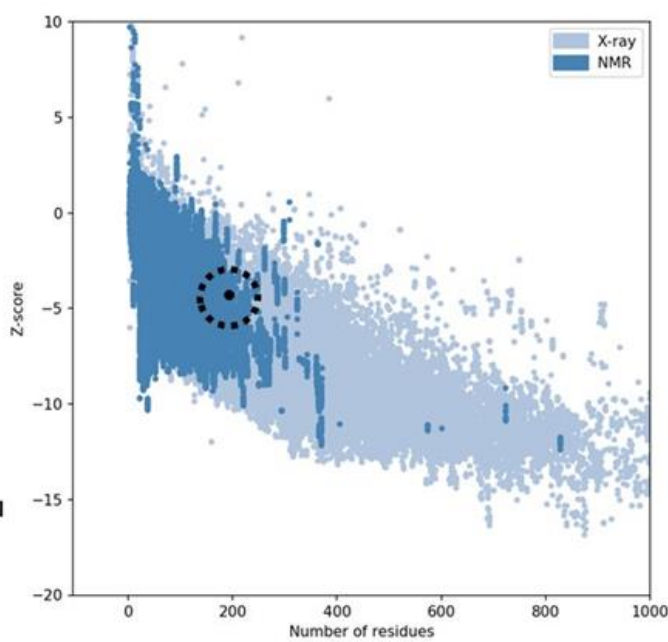

(c)

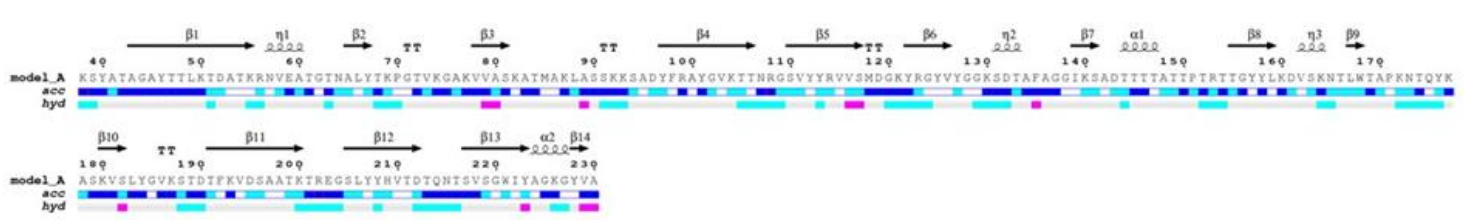

Figure 1. Molecular illustration of the Surface layer protein of Lactobacillus brevis KB290. (a) Cartoon image of SlpA with color impression showing the secondary structure in its native conformations; (b) ProSA based theoretical deduction of conformational validity with lower errors, the protein is shown at the subset X-ray and NMR protein database; (c) Primary structure representation with support to the above cartoon image.

The measured bond lengths between the protein's receptor and ligand protein-protein interactions were 3.0 to $4.0 \AA$ at phenylalanine of 2L9U (PHE-663) glycine of SlpA (GLY109), as shown in Figure 2. While the interactions of methionine of 2KNC (MET-686) with tyrosine of SlpA (TYR-127), as shown in Figure 3. This in-silico binding experiment showed that SlpA could strongly interfere in the binding of Erb2 and $\alpha$ IIB- $\beta 3$ at position alanine (ALA136) phenylalanine (PHE- 135). Besides, the binding sites of SlpA to Erb2 and $\alpha$ IIB- $\beta 3$ at amino acid residues 168-228 could prevent the binding of SlpA by the respective receptors. Although the mode of action of SlpA was reported as membrane dissociation of the microorganism, this in-silico binding result suggested an additional effort of SlpA via Erb2 and $\alpha$ IIB- $\beta 3$. Along with Cluspro interaction, a different PatchDock molecular docking server was used to deduce the global energies for the PPI interaction of the SlpA base on the surface geometries. The results are quite impressive as we expected for the Cluspro 2.0 webserver data was matched with the data from the PatchDock for the SlpA interaction with Erb2 showed the $\Delta \mathrm{G}$ (free energies) $-34.45 \mathrm{Kcal} / \mathrm{mol}$ and SlpA interaction with $\alpha \mathrm{IIB}-\beta 3$ showed the $\Delta \mathrm{G}-51.19$ $\mathrm{Kcal} / \mathrm{mol}$, the results are compared in Table 2. 
(a)
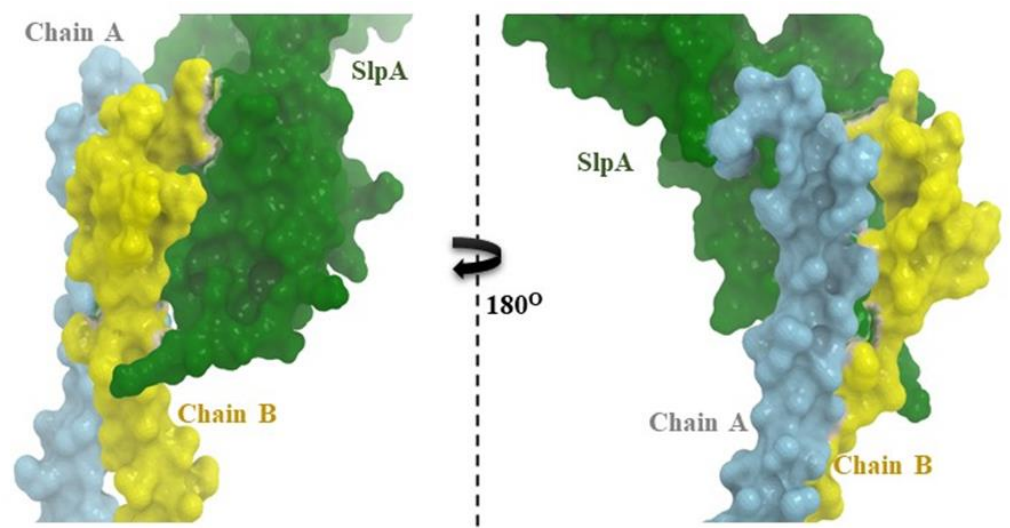

(b)

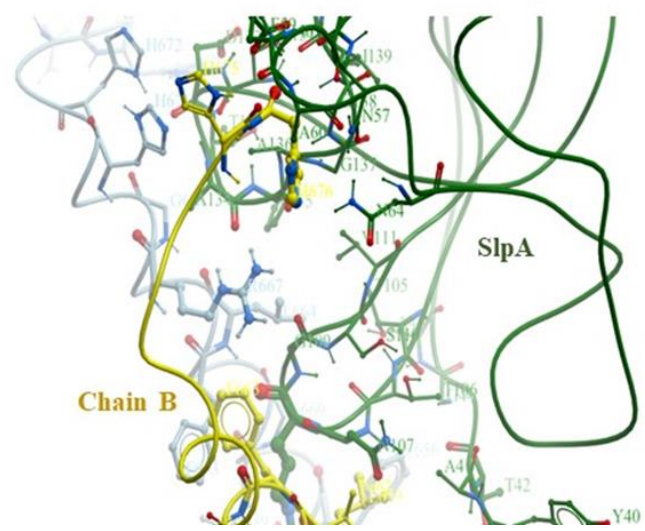

Figure 2. SlpA docking (color-coded for dark green) with Erb2 (EGFR/ERBB) functional transmembrane domain (which represented the heterodimeric protein chains in color-coded with yellow [chain A] and cyan blue [chain B]). (a) Surface representation of the molecular docking, contact surface was represented with pale yellow color-coded; (b) cartoon representation with primary structure showed the interacted amino acids at their respective distances.

(a)

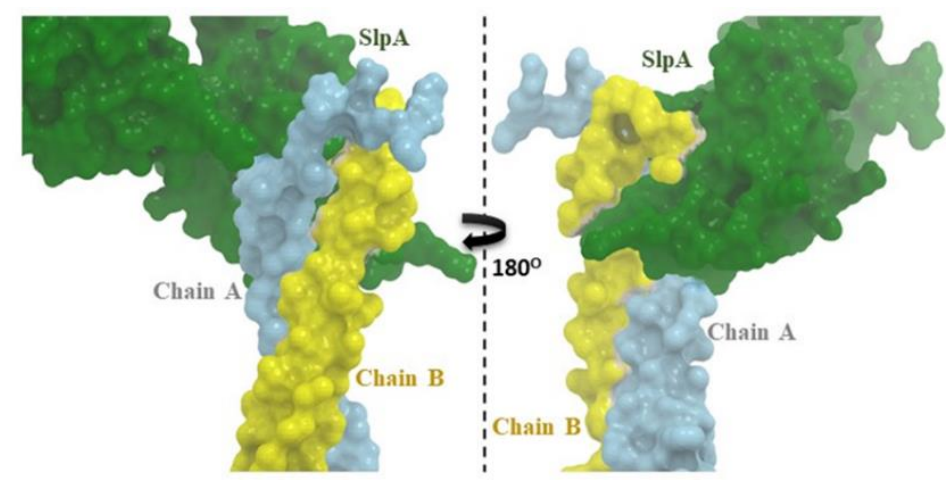

(b)

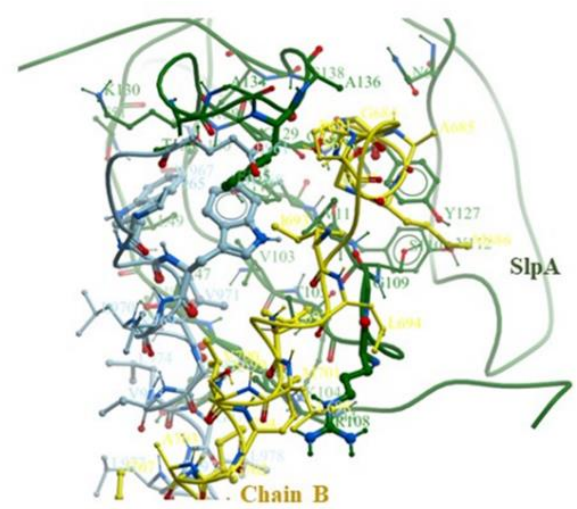

Figure 3. SlpA docking (color-coded for dark green) with the $\alpha$ IIB- $\beta 3$ functional transmembrane domain of platelets (which represented the heterodimeric protein chains in color-coded with yellow [chain A] and cyan blue [chain B]). (a) Surface representation of the molecular docking, contact surface was represented with pale yellow color-coded; (b) cartoon representation with primary structure showed the interacted amino acids at their respective distances. 
In support of the molecular docking, the root-mean-square fluctuation was presented in Figure 4 for Erb 2 and Figure 5 for $\alpha$ IIB- $\beta 3$ through the CABS flex 2.0 web server, which showed the information on the flexibility and rigidity of the PPI through the coarse-grained protein modeling. The output results are plotted concerning the SlpA bounded receptor, and unbounded receptors are compared, showing the considerable fluctuations in the SlpA structure in bounded form rather than in a free state. The residual contact points are shown in Fig ESM_3. This suggests the higher conformations rigidity of the SlpA suitable for the binding associations mentioned in the above molecular docking concept.

(a)

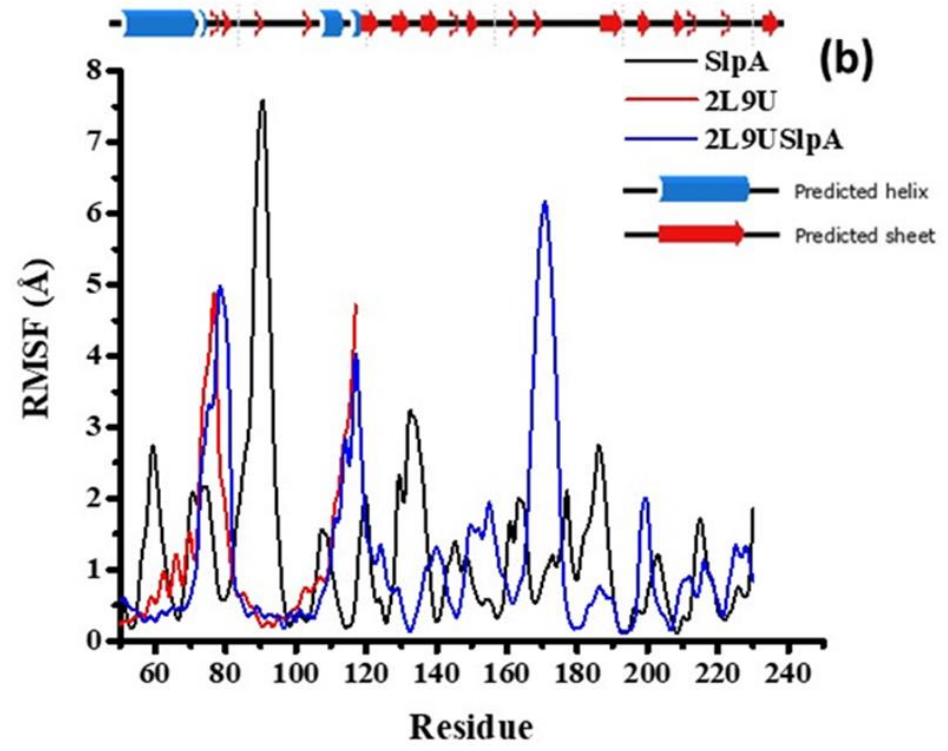

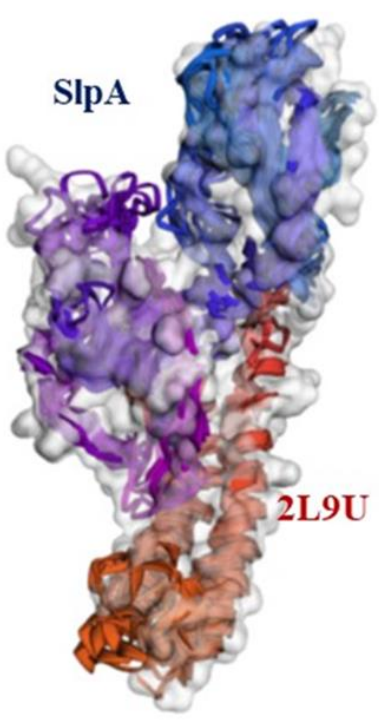

Figure 4. Molecular dynamics with CABS flex server 2.0 representations for rmsf based conformational coarse grain fluctuations for the flexibility and rigidity of the SlpA protein bounded and unbounded form with the receptors Erb2 transmembrane domain. (a) rmsf vs residual plots with lower flexibilities at their bounded form of SlpA protein; (b) Cartoon.

(a)

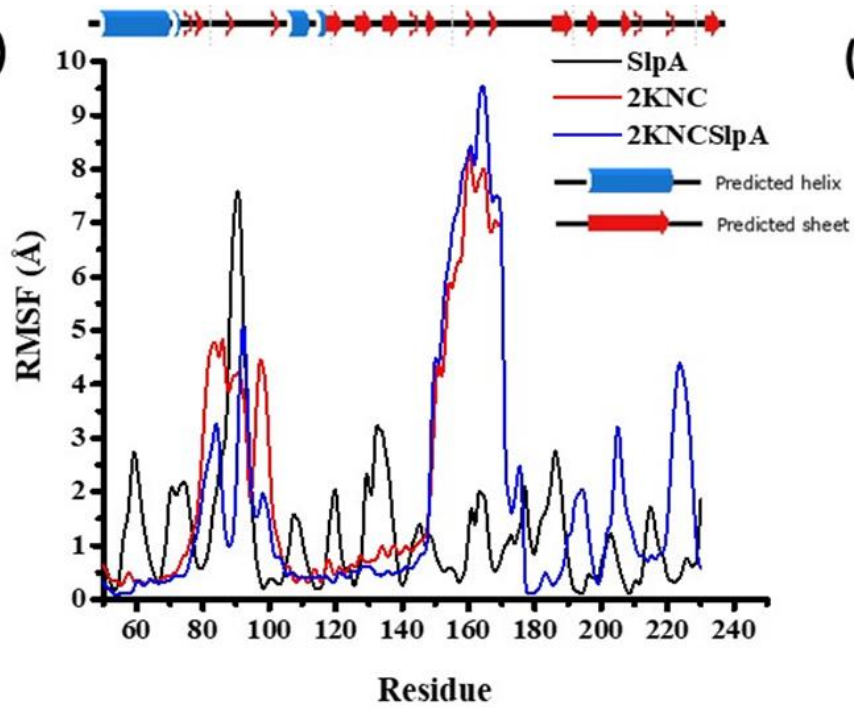

(b)

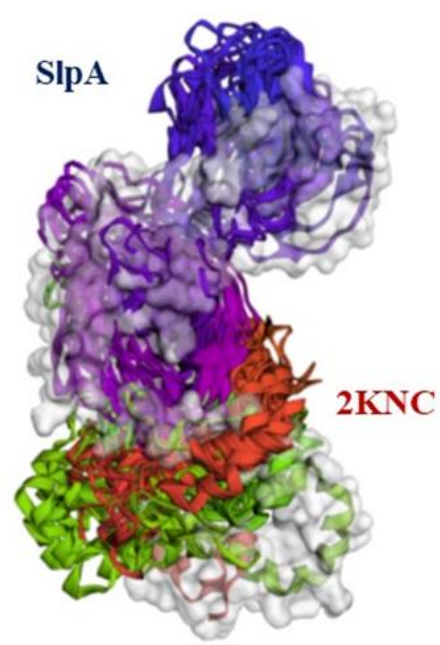

Figure 5. Molecular dynamics with CABS flex server 2.0 representations for rmsf based conformational coarse grain fluctuations for the flexibility and rigidity of the SlpA protein bounded and unbounded form with the receptors $\alpha$ IIB- $\beta 3$ transmembrane domain. (a) rmsf vs. residual plots with lower flexibilities at their bounded form of SlpA protein; (b) Cartoon /Surface representations of initial to final fluctuations shown in the group embed form of the PPI.

Based on the results, as mentioned above. The interaction perspectives and application of the SlpA PPI, few works of literature have said this study's interaction. Erb2 and Epidermal 
growth factor receptors are the potential receptors in treating cancer and related infections. The outer surfaces of the cells in cancer are upregulated, providing a broad scope to the activity of the drugs specific to the EGFR [47, 48]. Lactobacillus, one of the gut microorganisms, can access the EGFR, virtually shown in this docking study. The anti-inflammatory effect of the SlpA had been proved by binding to the $\alpha$ IIB- $\beta 3$ receptor of platelet cells. Studies from Rubio et al. (2017) discussed the importance of the surface layer protein, which shows cytotoxicity when surface layer protein was incubated with the breast cancer cells MDA-MB-231 through the epidermal growth receptors [49-51]. Altin et al. (1997) shown the effect of Slps in T-cell activation through the similar receptor mechanism [17], Li et al. (2011) suggested the inhibition of the Caco-2 cells [46], Zhong et al. (2014) demonstrated the lactic acid bacteria shows the anti-tumor activity towards the colorectal cancers through the PPI [31]. The human blood group A, trisaccharide, acts as a receptor for the Slp of a human L. brevis considering the nine $\mathrm{N}$ terminal amino acids of the Slp [28].

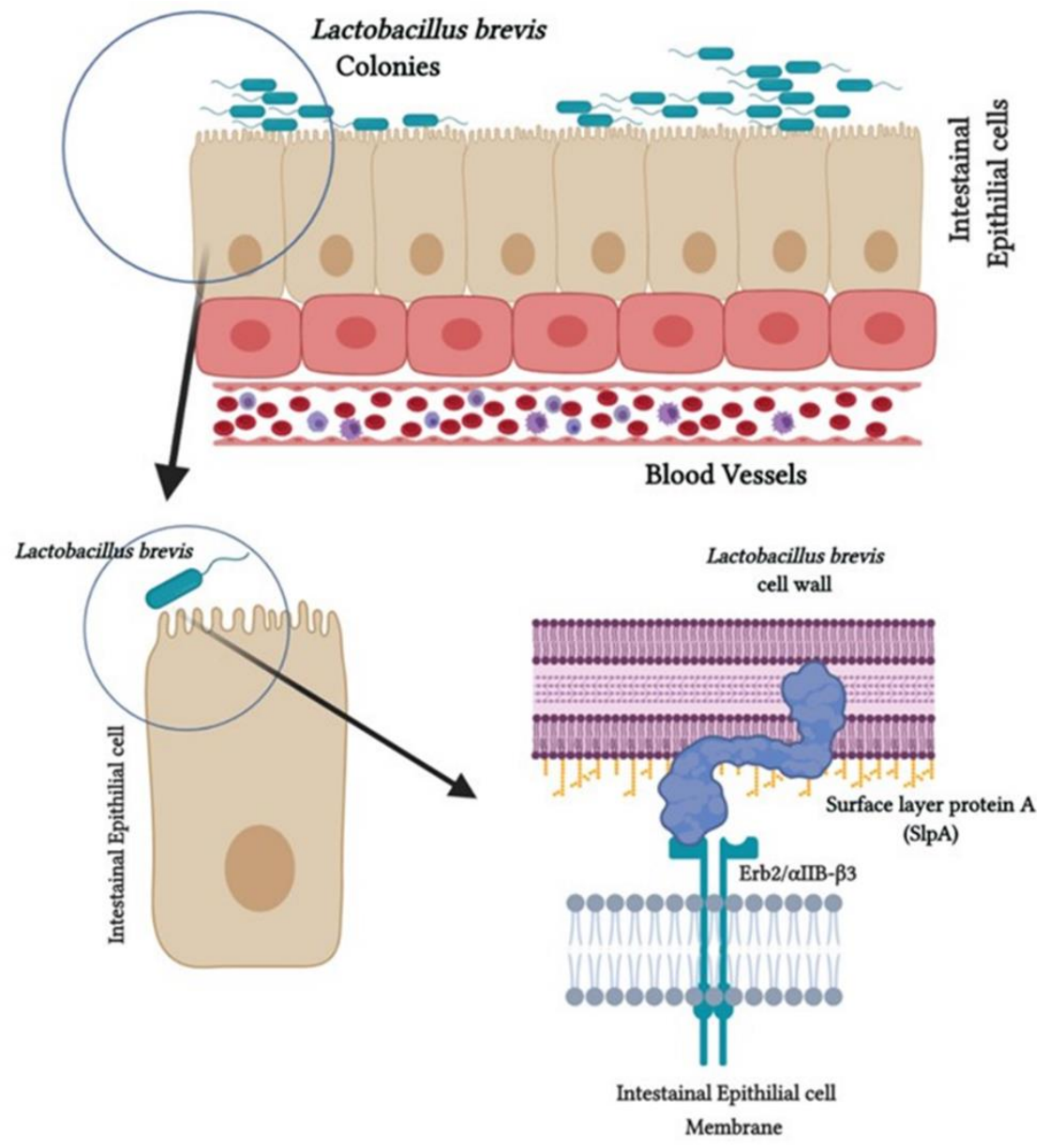

Figure 6. Graphical abstract of the SlpA protein's theoretical binding with the Erb2/ $\alpha$ IIB- $\beta 3$ transmembrane domain at their respective resolutions.

Table 1. Molecular docking solutions of ClusPro 2.0 coefficient weights through lowest energies of PPI clusters

\begin{tabular}{l|l|l|l|l} 
Protein-protein Interactions & Balanced & Electrostatic & Hydrophobic & Van der Waals \\
\hline 2L9U_SlpA & -1048 & -1120 & -1507 & -138.4 \\
\hline 2KNC_SlpA & -1111.6 & -1082 & -1714 & -435
\end{tabular}

When involved in the expression of several proinflammatory cytokines and a therapeutic target in a wide range of autoinflammatory diseases in the presence of L. helveticus MIMLh5 in Caco-2 (the human epithelial cell line) results in reduced levels of transcriptional factor NF- $\kappa$ B activity [50], and that other studies revealed the significant scope of Lactobacillus 
sp. This supports that the movement of the SlpA was so peculiar in compatible binding towards the upregulation or downregulation of the specific markers of the cancers [52-54]. These PPI interactions are shown here through this computational study. Further work is in progress in developing the reaction mechanism towards inhibition or cytotoxicity, leading to the treatment of the cancers based on the comprehensive discussion on the activity of the bacterial protein SlpA and other probiotics[55-58]. This study can help understand the host-microbial relationships in treating dreadful diseases like cancers and other GIT disorders with normal microbiota. Further proof of concept in this study's PPI is needed through wet lab analysis to observe the further applications in the host-microbial interactions $[59,60]$.

Table 2. Molecular docking solutions of PatchDock coefficients through free energies of PPI

\begin{tabular}{l|l|l} 
Protein-protein Interactions & $\boldsymbol{\Delta G}$ & ACE \\
\hline 2L9U_SlpA & -34.45 & -2.49 \\
\hline 2KNC_SlpA & -51.19 & -7.97
\end{tabular}

\section{Conclusions}

In conclusion, for this study, Lactobacillus is considered the probiotic bacteria involved in the GIT tract's homeostasis through symbiotic and normal microbial relationships in human beings and other higher-order species. Based on the literature, the L. brevis and other lactobacillus species' binding activity involves regulating the cell surface receptor to activate proinflammatory and immunomodulatory effects. This study made an addon note for the molecular interactions through the molecular docking and simulation studies in a fundamental understating of the SlpA PPI concept.

\section{Funding}

This research received no external funding.

\section{Acknowledgments}

The authors acknowledges Indian council of medical research though senior research fellowship (ICMR-SRF-2020) for the support to continue and develop this research work

\section{Conflicts of Interest}

The authors declare no conflict of interest.

\section{References}

1. Haraguchi, N.; Inoue, H.; Tanaka, F.; Mimori, K.; Utsunomiya, T.; Sasaki, A.; Mori, M. Cancer stem cells in human gastrointestinal cancers. Human cell 2006,19, 24-29. https://doi.org/10.1111/j.17490774.2005.00004.x.

2. Spratlin, J.L.; Serkova, N.J.; Eckhardt, S.G. Clinical applications of metabolomics in oncology: a review. Clinical cancer research 2009, 15, 431-440. https://doi.org/10.1158/1078-0432.CCR-08-1059.

3. Kovacs, E.; Zorn, J.A.; Huang, Y.; Barros, T.; Kuriyan, J. A structural perspective on the regulation of the epidermal growth factor receptor. Annual review of biochemistry 2015 84, 739-764. https://doi.org/10.1146/annurev-biochem-060614-034402.

4. Huifang, W.; Yuhan, N.; Jie P.; Qinpei, L.; Rongrong, L.Antibacterial effects of lactobacillus acidophilus surface-layer protein in combination with nisin against staphylococcus aureus. LWT 2020, 124, 109208. https://doi.org/10.1016/j.lwt.2020.109208. 
5. Wang, H.; Zhang, L.; Li, Q.; Xu, S.; Lu, R. Surface-layer protein produced by Lactobacillus crispatus JCM 2009 ameliorates lipopolysaccharide-induced inflammation through autophagy cross-talk with the NF- $\mathrm{KB}$ signaling pathway. International Journal of Biological Macromolecules 2021, 166, 633-640. https://doi.org/10.1016/j.ijbiomac.2020.10.221.

6. Meng, J.; Wang, Y.Y.; Hao, Y.P. Protective function of surface layer protein from Lactobacillus casei fb05 against intestinal pathogens in vitro. Biochemical and Biophysical Research Communications 2021, 546, 1520. https://doi.org/10.1016/j.bbrc.2021.01.101.

7. Herbst, R.S. Review of epidermal growth factor receptor biology. International Journal of Radiation Oncology Biology Physics 2004, 59, S21-S26. https://doi.org/10.1016/j.ijrobp.2003.11.041.

8. Wieduwilt, M.; Moasser, M. The epidermal growth factor receptor family: biology driving targeted therapeutics. Cellular and Molecular Life Sciences 2008, 65, 1566-1584. https://doi.org/10.1007/s00018008-7440-8.

9. Yewale, C.; Baradia, D.; Vhora, I.; Patil, S.; Misra, A. Epidermal growth factor receptor targeting in cancer: a review of trends and strategies. Biomaterials 2013, 34, 8690-707. https://doi.org/10.1016/j.biomaterials.2013.07.100

10. Altin, J.G.; Sloan, E.K. The role of CD45 and CD45-associated molecules in T cell activation. Immunology and cell biology 1997, 75, 430-445. https://doi.org/10.1038/icb.1997.68.

11. Holmes, N. CD45: all is not yet crystal clear. Immunology 2006, 117, 145-155. https://doi.org/10.1111/j.1365-2567.2005.02265.x.

12. Yang, M.; Liu, P.; Huang, P. Cancer stem cells, metabolism, and therapeutic significance. Tumor Biology, 2016, 37, 5735-5742. https://doi.org/10.1007/s13277-016-4945-X.

13. Zhang, T.; Pan, D.; Yang, Y.; Jiang, X.; Zhang, J.; Zeng, X.; Wu, Z.; Sun, Y.; Guo, Y. Effect of Lactobacillus acidophilus CICC 6074 S-layer protein on colon cancer HT-29 cell proliferation and apoptosis. Journal of agricultural and food chemistry 2020, 68, 2639-2647. https://doi.org/10.1021/acs.jafc.9b06909.

14. Qi, S.R.; Cui, Y.J.; Liu, J.X.; Luo, X.; Wang, H.F. Lactobacillus rhamnosus GG components, SLP, gDNA and $\mathrm{CpG}$, exert protective effects on mouse macrophages upon lipopolysaccharide challenge. Letters in applied microbiology, 2020, 70, 118-127. https://doi.org/10.1111/lam.13255.

15. Ge, Y.; Gong, M.; Zadeh, M.; Li, J.; Abbott, J.R.; Li, W.; Morel, L.; Sonon, R.; Supekar, N.T.; Azadi, P.; Wang, Y. Regulating colonic dendritic cells by commensal glycosylated large surface layer protein A to sustain gut homeostasis against pathogenic inflammation. Mucosal Immunol 2020, 13, 34-46. https://doi.org/10.1038/s41385-019-0210-0.

16. Clarke, M.B.; Sperandio, V. Events at the host-microbial interface of the gastrointestinal tract III. Cell-to-cell signaling among microbial flora, host, and pathogens: there is a whole lot of talking going on. American Journal of Physiology-Gastrointestinal and Liver Physiology 2005, 288, G1105-G1109. https://doi.org/10.1152/ajpgi.00572.2004.

17. Moran, A.; Gupta, A.; Joshi, L. Sweet-talk: role of host glycosylation in bacterial pathogenesis of the gastrointestinal tract. Gut 2011, 60, 1412-25. https://doi.org/10.1136/gut.2010.212704.

18. Duncan, H.E.; Edberg, S.C. Host-microbe interaction in the gastrointestinal tract. Critical reviews in microbiolog 1995, 21, 85-100. https://doi.org/10.3109/10408419509113535.

19. Åvall-Jääskeläinen, S.; Kylä-Nikkilä, K.; Kahala, M.; Miikkulainen-Lahti, T.; Palva, A. Surface display of foreign epitopes on the Lactobacillus brevis S-layer. Applied and Environmental Microbiology 2002, 68, 5943-51. https://doi.org/10.1128/AEM.68.12.5943-5951.2002.

20. Zhang, T.; Pan, D.; Yang, Y.; Jiang, X.; Zhang, J.; Zeng, X.; Wu, Z.; Sun, Y.; Guo, Y. Effect of Lactobacillus acidophilus CICC 6074 S-layer protein on colon cancer HT-29 cell proliferation and apoptosis. Journal of agricultural and food chemistry 2020, 68, 2639-2647. https://doi.org/10.1021/acs.jafc.9b06909.

21. Qi, S.R.; Cui, Y.J.; Liu, J.X.; Luo, X.; Wang, H.F. Lactobacillus rhamnosus GG components, SLP, gDNA and $\mathrm{CpG}$, exert protective effects on mouse macrophages upon lipopolysaccharide challenge. Letters in applied microbiology 2020, 70, 118-127. https://doi.org/10.1111/lam.13255.

22. Åvall-Jääskeläinen, S.; Palva, A. Lactobacillus surface layers and their applications. FEMS Microbiology Review 2005, 29, 511-529. https://doi.org/10.1016/j.fmrre.2005.04.003.

23. Hynönen, U.; Palva, A. Lactobacillus surface layer proteins: structure, function and applications. Applied microbiology and biotechnology 2013, 97, 5225-5243. https://doi.org/10.1007/s00253-013-4962-2.

24. Taverniti, V.; Stuknyte, M.; Minuzzo, M.; Arioli, S.; De Noni, I.; Scabiosi, C.; et al. S-layer protein mediates the stimulatory effect of Lactobacillus helveticus MIMLh5 on innate immunity. Applied and environmental microbiology 2013, 79, 1221-1231. https://doi.org/10.1128/AEM.03056-12. 
25. Hollmann, A.; Delfederico, L.; Miyoshi, A.; Disalvo, E.A.; DeAntoni, G.; Semorile, L.; et al. S-layer proteins from lactobacilli as vaccine delivery systems. International Journal of Microbiology Research 2010, 2, 3043. https://doi.org/10.9735/0975-5276.2.2.30-43.

26. Åvall-Jääskeläinen, S.; Hynönen, U.; Ilk, N.; Pum, D.; Sleytr, U.B.; Palva, A. Identification and characterization of domains responsible for self-assembly and cell wall binding of the surface layer protein of Lactobacillus brevisATCC 8287. BMC microbiology 2008, 8. https://doi.org/10.1186/1471-2180-8-165.

27. Ryan, A.; Lynch, M.; Smith, S.M.; Amu, S.; Nel, H.J.; McCoy, C.E.; et al. A role for TLR4 in Clostridium difficile infection and the recognition of surface layer proteins. PLoS Pathog 2011, 7, e1002076. https://doi.org/10.1371/journal.ppat.1002076.

28. Fagan, R.P.; Fairweather, N.F. Biogenesis and functions of bacterial S-layers. Nature Reviews Microbiology 2014, 12, 211-222. https://doi.org/10.1038/nrmicro3213.

29. Zhong, L.; Zhang, X.; Covasa, M. Emerging roles of lactic acid bacteria in protection against colorectal cancer. World J Gastroenterol 2014, 20, 7878-7886. https://doi.org/10.3748/wjg.v20.i24.7878.

30. Gerbino, E.; Carasi, P.; Mobili, P.; Serradell, M.; Gómez-Zavaglia, A. Role of S-layer proteins in bacteria. World Journal of Microbiology and Biotechnology 2015, 31, 1877-8187. https://doi.org/10.1007/s11274015-1952-9.

31. Burley, S.K.; Berman, M.; Bhikadiya, C.; Bi, C.; Chen, L.; Di Costanzo, L.; et al. RCSB Protein Data Bank: biological macromolecular structures enabling research and education in fundamental biology, biomedicine, biotechnology and energy. Nucleic acids research 2019, 47, D464-D474. https://doi.org/10.1093/nar/gky1004.

32. Jenuth, J.P. The NCBI. Bioinformatics Methods and Protocols: Springer 2000, 301-312. https://doi.org/10.1385/1592591922.

33. Yakabe, T.; Moore, E.; Yokota, S.; Sui, H.; Nobuta, Y.; Fukao, M.; et al. Safety assessment of Lactobacillus brevis KB290 as a probiotic strain. Food and chemical toxicology 2009, 47, 2450-2453. https://doi.org/10.1016/j.fct.2009.07.001.

34. Kiefer, F.; Arnold, K.; Künzli, M.; Bordoli, L.; Schwede, T. The SWISS-MODEL Repository and associated resources. Nucleic acids research 2009, 37, D387-D392. https://doi.org/10.1093/nar/gkn750.

35. Davis, I.W.; Leaver-Fay, A.; Chen, V.B.; Block, J.N.; Kapral, G.J.; Wang, X.; et al. MolProbity: all-atom contacts and structure validation for proteins and nucleic acids. Nucleic acids research 2007, 35, W375W383. https://doi.org/10.1093/nar/gkm216.

36. Benkert, P.; Künzli, M.; Schwede, T. QMEAN server for protein model quality estimation. Nucleic acids research, 2009, 37, W510-W514. https://doi.org/10.1093/nar/gkp322.

37. Wiederstein, M.; Sippl, M.J. ProSA-web: interactive web service for the recognition of errors in threedimensional structures of proteins. Nucleic acids research 2007, 35, W407-W410. https://doi.org/10.1093/nar/gkm290.

38. Mineev, K.; Khabibullina, N.; Lyukmanova, E.; Dolgikh, D.; Kirpichnikov, M.; Arseniev, A.S. Spatial structure and dimer-monomer equilibrium of the ErbB3 transmembrane domain in DPC micelles. Biochimica et Biophysica Acta (BBA)-Biomembranes 2081-2088. https://doi.org/10.1016/j.bbamem.2011.04.017.

39. Yang, J.; Ma, Y-Q.; Page, R.C.; Misra, S.; Plow, E.F.; Qin, J. Structure of an integrin $\alpha I I b \beta 3$ transmembranecytoplasmic heterocomplex provides insight into integrin activation. Proceedings of the National Academy of Sciences 2009, 106, 17729-17734. https://doi.org/10.1073/pnas.0909589106.

40. BIOVIA DS. Discovery Studio Client; 2.5. 0.9164. Dassault Systèmes: San Diego, CA, USA. 2005.

41. Guex, N.; Peitsch, M.C. SWISS-MODEL and the Swiss-Pdb Viewer: an environment for comparative protein modeling. Electrophoresis 1997, 18, 2714-2723. https://doi.org/10.1002/elps.1150181505.

42. Schneidman-Duhovny, D.; Inbar, Y.; Nussinov, R.; Wolfson, H.J. PatchDock and SymmDock: servers for rigid and symmetric docking. Nucleic acids research 2005, 33, W363-W367. https://doi.org/10.1093/nar/gki481.

43. Kuriata, A.; Gierut, A.M.; Oleniecki, T.; Ciemny, M.P.; Kolinski, A.; Kurcinski, M.; Kmiecik, S. CABS-flex 2.0: a web server for fast simulations of flexibility of protein structures. Nucleic acids research 2018, 46, W338-W343. https://doi.org/10.1093/nar/gky356.

44. Li, P.; Yin, Y.; Yu, Q.; Yang, Q. Lactobacillus acidophilus S-layer protein-mediated inhibition of Salmonellainduced apoptosis in Caco-2 cells. Biochemical and biophysical research communications 2011, 409, 142147. https://doi.org/10.1016/j.bbrc.2011.04.131. 
45. Pawson, T.; Scott, J.D. Signaling through scaffold, anchoring, and adaptor proteins. Science 1997, 278, 20752080. https://doi.org/10.1126/science.278.5346.2075.

46. Marinissen, M.J.; Gutkind, J.S. G-protein-coupled receptors and signaling networks: emerging paradigms. Trends in pharmacological sciences 2001, 22, 368-376. https://doi.org/10.1016/S0165-6147(00)01678-3.

47. Rubio, V.P.; Bravo, A.; Olmos, J. Identification of a Bacillus thuringiensis surface layer protein with cytotoxic activity against MDA-MB-231 Breast Cancer Cells. J Microbiol Biotechnol 2017, 27, 36-42. https://doi.org/10.4014/jmb.1607.07020.

48. Ausiello, C.M.; Cerquetti, M.; Fedele, G.; Spensieri, F.; Palazzo, R.; Nasso, M.; et al. Surface layer proteins from Clostridium difficile induce inflammatory and regulatory cytokines in human monocytes and dendritic cells. Microbes and infection 2006, 8, 2640-2646. https://doi.org/10.1016/j.micinf.2006.07.009.

49. Partrick, K.A.; Rosenhauer, A.M.; Auger, J.; Arnold, A.R.; Ronczkowski, N.M.; Jackson, L.M.; Lord, M.N.; Abdulla, S.M.; Chassaing, B.; Huhman, K.L.; Ingestion of probiotic (Lactobacillus helveticus and Bifidobacterium longum) alters intestinal microbial structure and behavioral expression following social defeat stress. Scientific Reports, 2021, 11(1), 1-12. https://doi.org/10.1038/s41598-021-83284-z

50. Cai, Z.; Wang, P.; Guo, Y.; Zeng, X.; Wu, Z.; Pan, D. S-layer protein modulates the stimulatory effects of Lactobacillus acidophilus CICC 6074 by triggering PKC signaling cascade in RAW 264.7 cells. Journal of Functional Foods 2020, 67, 103841. https://doi.org/10.1016/j.jff.2020.103841.

51. Wakai, T.; Kano, C.; Karsens, H.; Kok, J.; Yamamoto, N. Functional role of surface layer proteins of Lactobacillus acidophilus L-92 in stress tolerance and binding to host cell proteins. Bioscience of Microbiota, Food and Health 2020, 40, 33-42. https://doi.org/10.12938/bmfh.2020-005.

52. Mobarak Qamsari, E.; Kasra Kermanshahi, R.; Erfan, M.; Ghadam, P. Microencapsulation of Omeprazole by Lactobacillus acidophilus ATCC 4356 surface layer protein and evaluation of its stability in acidic condition. Iranian Journal of Pharmaceutical Research 2020, 19, 240-254. https://doi.org/10.22037/ijpr.2019.111681.13306.

53. Liu, Q.; Jiang, Y.; Yang, W.; Liu, Y.; Shi, C.; Liu, J.; Gao, X.; Huang, H.; Niu, T., Yang, G.; Wang, C. Protective effects of a food-grade recombinant Lactobacillus plantarum with surface displayed AMA1 and EtMIC2 proteins of Eimeria tenella in broiler chickens. Microbial cell factories 2020, 19. https://doi.org/10.1186/s12934-020-1297-4.

54. Zhuo, S.; Xun, M.; Li, M.; Kong, X.; Shao, R.; Zheng, T.; Pan, D.; Li, J.; Li, Q. Rapid and label-free optical assay of S-layer protein with high sensitivity using $\mathrm{TiO} 2$-coated porous silicon-based microfluidic biosensor. Sensors and Actuators B: Chemical 2020, 321, 128524. https://doi.org/10.1016/j.snb.2020.128524.

55. Klotz, C.; Goh, Y.J.; O'Flaherty, S.; Barrangou, R. S-layer associated proteins contribute to the adhesive and immunomodulatory properties of Lactobacillus acidophilus NCFM. BMC microbiology 2020, 20, 1-13. https://doi.org/10.1186/s12866-020-01908-2.

56. Gordillo, T.B.; Palumbo, M.C.; Allievi, M.C.; Do Porto, D.A.F.; Ruzal, S.M.; Palomino, M.M. Strategies to display heterologous proteins on the cell surface of lactic acid bacteria using as anchor the C-terminal domain of Lactobacillus acidophilus SlpA. World Journal of Microbiology and Biotechnology 2020, 36, 1-11. https://doi.org/10.1007/s11274-020-02945-9.

57. Bolla, P.A.; Sanz, A.; Huggias, S.; Ruggera, J.F.; Serradell, M.A.; Casella, M.L. Regular arrangement of Pt nanoparticles on S-layer proteins isolated from Lactobacillus kefiri: Synthesis and catalytic application. Molecular Catalysis 2020, 481, 110262. https://doi.org/10.1016/j.mcat.2018.12.011.

58. Chen, Y.; Huang, K.; Chen, L.K.; Wu, H.Y.; Hsu, C.Y.; Tsai, Y.S.; Ko, W.C.; Tsai, P.J. Membrane cholesterol is crucial for Clostridium difficile surface layer protein binding and triggering inflammasome activation. Frontiers in Immunology 2020, 11. https://doi.org/10.3389/fimmu.2020.01675.

59. Mindur, J.E.; Yadav, S.K.; Ito, N.; Senoh, M.; Kato, H.; Dhib-Jalbut, S.; Ito, K. Surface Layer Protein A Expressed in Clostridioides difficile DJNS06-36 Possesses an Encephalitogenic Mimotope of Myelin Basic Protein. Microorganisms 2021, 9, 34. https://doi.org/10.3390/microorganisms9010034. 